\title{
A systematic review on hospital inefficiency in the Eastern Mediterranean Region: sources and solutions
}

\author{
Hamid Ravaghi ${ }^{1}$, Mahnaz Afshari ${ }^{*}$ (D), Parvaneh Isfahani ${ }^{2}$ and Victoria D. Bélorgeot ${ }^{3}$
}

\begin{abstract}
Background: Evaluating hospital efficiency is a process to optimize resource utilization and allocation. This is vital due to hospitals being the largest financial cost in a health system. To limit avoidable uses of hospital resources, it is important to identify the sources of hospital inefficiencies and to put in place measures towards their reduction and elimination. Thus, the purpose of this research is to examine the sources of hospital inefficiency in the Eastern Mediterranean Region, and existing strategies tackling this issue.

Methods: In this study, the electronic databases MEDLINE (via PubMed), Web of Science, Embase, Google, Google Scholar, and reference lists of selected articles, were explored. Studies on inefficiency, sources of inefficiency, and strategies for inefficiency reduction in the Eastern Mediterranean region hospitals, published between January 1999 and May 2018, were identified. A total of 1466 articles were selected using the initial criteria. After further reviews based on the inclusion and exclusion criteria, 56 studies were eligible for this study. The chosen studies were conducted in Iran $(n=35)$, Saudi Arabia $(n=5)$, Tunisia $(n=5)$, Jordan $(n=4)$, Pakistan $(n=2)$, the United Arab Emirates, Palestine, Iraq, Oman, and Afghanistan ( $n=1$ each). These studies were analyzed using content analysis in MAXQDA 10.

Results: The analysis showed that approximately $41 \%$ of studies used data envelopment analysis (DEA) to measure hospital efficiency. Sources of hospital inefficiency were divided into four categories for analysis: Hospital products and services, hospital workforce, hospital services delivery, and hospital system leakages.

Conclusion: This study has revealed some sources of inefficiency in the Eastern Mediterranean Region hospitals. Inefficiencies are thought to originate from excess workforce, excess beds, inappropriate hospital sizes, inappropriate workforce composition, lack of workforce motivation, and inefficient use of health system inputs. It is suggested that health policymakers and managers use this evidence to develop appropriate strategies towards the reduction of hospital inefficiency.
\end{abstract}

Keywords: Efficiency, Hospitals, Eastern Mediterranean countries, Systematic review

\section{Background}

Hospitals are an essential component of health systems, while also being the most costly. They account for $50-$ $80 \%$ of total health expenditures [1]. Hospital costs continue to rise due to the development of new technologies. New diagnostic and therapeutic methods are implemented to combat the rising proportion of chronic

\footnotetext{
* Correspondence: afshari.m@tak.iums.ac.ir

'Department of Health Service Management, School of Health Management and Information Sciences, Iran University of Medical Sciences, Tehran, Iran Full list of author information is available at the end of the article
}

diseases, the increasing demand for health services, and the subsequent medical errors [2]. This has become a primary challenge and concern for governments [3].

Hospitals in the Eastern Mediterranean Region (EMR) differ in size, proprietorship, assignment, and performance. The total number of hospital beds is estimated to be 740,000 and, except for Lebanon, the majority of hospital beds are in the public sector $(80 \%)$, with the remaining in private for-profit (18\%) and private not-for-profit $(2 \%)$ hospitals. The range of hospital beds per 10,000 population vary from 3.9 to 32 in 22 countries in the EMR. 
Hospitals also vary widely in size, location (rural and urban), resources, specialization (general versus specialty hospitals) and organization, as well as their position in the health system (first-level hospitals, secondary care hospitals and large teaching institutions) [4]. A large proportion of hospitals are financed by the government, but out-ofpocket payments are rising due to limited public sector resources [5]. This leads to limited access to health services for vulnerable communities. Private hospitals in the EMR are usually small to medium size and located in capitals and other large cities. These hospitals are not the result of comprehensive health system planning, as such, they can also lead to inequity in access to healthcare. Most countries in the EMR have addressed inequalities by implementing reforms to increase productivity, transparency, and cost flexibility [5-7]. To facilitate this process and increase hospital efficiency, it is necessary to provide the healthcare sector with additional resources and management tools.

According to Farrell (1957), efficiency is defined as "the firm's success to produce the maximum feasible amount of output from a given amount of input or producing a given amount of output using the minimum level of inputs where both the inputs and the outputs are correctly measured" [8]. Three different types of efficiency were defined by Farrell: technical efficiency, allocative efficiency, and economic efficiency. Technical efficiency is the ability of a business to gain a maximum output from the specific input. In contrast, allocative efficiency refers to the directing of resources toward products or services with the highest demand. Economic efficiency is allocative efficiency and technical efficiency from a joint unit of cost efficiency. An organization has an economic efficiency Which be efficient in terms of both technical and allocational [8]. In general, different methods have been used to measure hospital efficiency: Data Envelopment Analysis (DEA), Stochastic Frontier Analysis (SFA), and measures of performance, such as Pabon Lasso's model. DEA is a non-parametric linear programming method used to evaluate the efficiency of decision-making units $[8,9]$. SFA is parametric and calculates the difference between the organization's predicted and expected outputs [10]. Pabon Lasso's model (1986) assesses hospital performance using three performance indicators: bed occupancy rate (BOR), bed turnover rate (BTR), and average length of stay (ALS) [11].

A decline in hospital efficiency has been observed worldwide. In a global report by the World Health Organization (WHO) published in 2010, 10 sources of hospital inefficiency were identified: (1) underuse or overpricing of generic drugs; (2) use of substandard or counterfeit drugs; (3) inappropriate and ineffective drug use; (4) overuse or oversupply of equipment, investigations and procedures; (5) inappropriate or costly workforce mix, unmotivated worker; (6) inappropriate hospital admissions or length of stay; (7) inappropriate hospital size (low use of infrastructure); (8) medical errors and suboptimal quality of care; (9) waste, corruption and fraud; and (10) inefficient mix or inappropriate level of strategies [12]. However, thus far there has not been a comprehensive review to assess the source of hospital inefficiency in the EMR. This study aims to comprehensively identify the sources of hospital inefficiency in the EMR, and compare these to previously identified sources of hospital inefficiency. This will provide insight into the current condition of healthcare in this region.

According to the aforementioned WHO report, hospital efficiency in the EMR is low, particularly in low and middle-income countries (LMICs) [5]. To increase hospital efficiency in a context of rising costs and limited resources, it is necessary to identify sources of inefficiency and to suggest improvement strategies. Identifying these sources and identifying improvements are the objectives of this study.

\section{Methods}

This is a systematic review of existing evidence on hospital inefficiency in the EMR. This study recruited English peer-reviewed articles published between January 1999 and May 2018. To identify relevant articles, a database search was conducted in MEDLINE (via PubMed) (Additional file 1), Web of Knowledge, Embase, Google and Google Scholar. Keywords used included "efficiency", "productivity", "inefficiency", "hospital", "data envelopment analysis", "Pabon Lasso", and "stochastic frontier analysis". Moreover, the reference lists of selected articles were searched for relevant papers. Economic journals in the field of health economy and efficiency such as the Journal of the Knowledge Economy, the American Journal of Economics and Business Administration, Cost Effectiveness and Resource Allocation, and the International Journal of Economics and Financial Issues were searched individually. An initial review was conducted to determine the scope of the study, and no study published before 1999 was found. Therefore, the review included studies between 1999 and May 2018.

Following the screening of 1087 identified articles, 80 full texts were assessed for eligibility. After assessing these articles, 56 were included in the review. The screening process and search results are shown in the PRISMA Flow Diagram [13] of Fig. 1.

A data extraction form with entries for the first author, year of publication, country of study, data collection method, number of hospitals studied, inputs and outputs for efficiency, sources of hospital inefficiency, and factors affecting efficiency, was used to collect data from the 


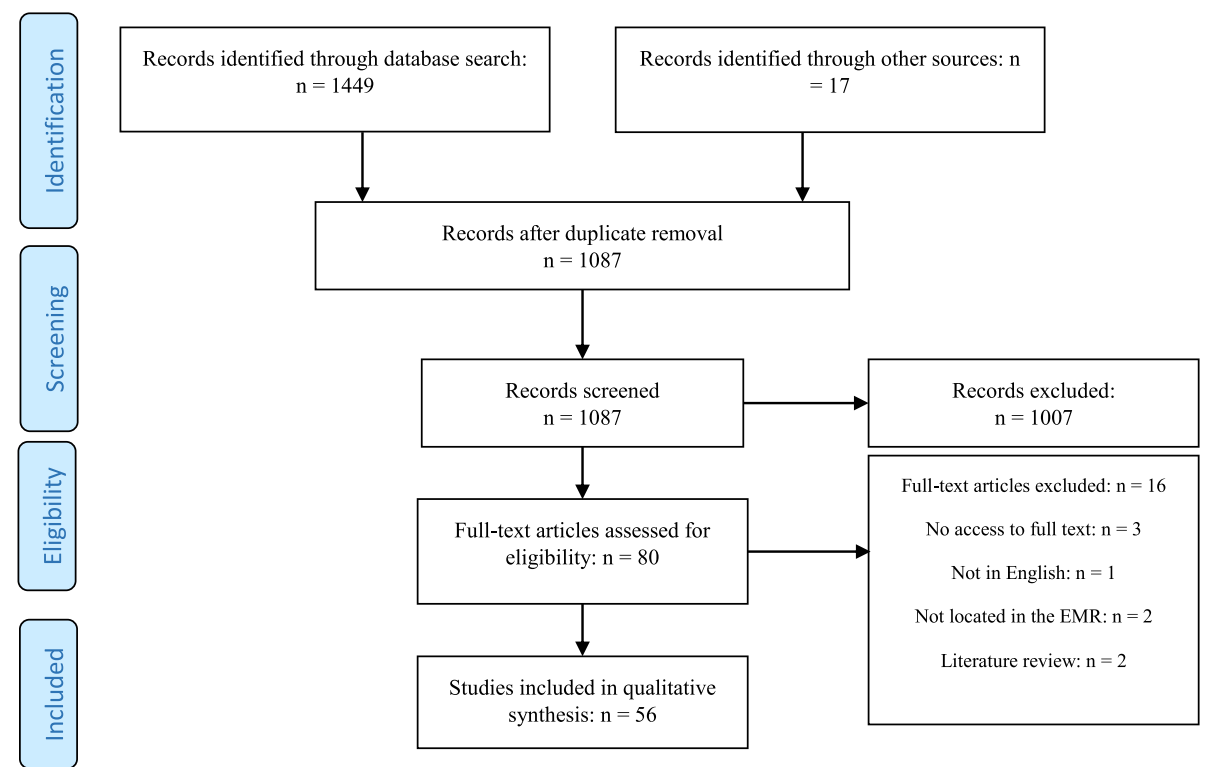

Fig. 1 PRISMA Flow Diagram: Database search and article selection process

selected studies. For higher reliability, two researchers independently extracted data from a randomly selected sample of the chosen articles. Any disagreements were solved by discussion and consensus and, if necessary, by a third reviewer.

Mitton et al.'s fifteen-point scale [14] was used for quality appraisal. The criteria used to assess quality included: literature review and identification of research gaps; research question and design, validity and reliability; data collection; population and sampling; and analysis and reporting of results. These criteria were rated 0 (not present or reported), 1 (present but low quality), 2 (present and mid-range quality), or 3 (present and high quality). Articles were rated independently by two researchers using the article quality rating sheet. Given that the review was qualitative, articles were not removed at this stage, but more weight was given to articles with a quality rating of 10 or above in the data analysis and interpretation of results.

The data were analyzed using qualitative content analysis. Data were coded and managed using MAXQDA 10 for Windows (VERBI GmbH, Berlin, Germany), and themes and subthemes were extracted to identify patterns and relationships between themes.

\section{Results}

A total of 56 articles on hospital efficiency in the EMR, published between January 1999 and May 2018, were reviewed. A large number of studies (91\%) were published after 2010. The reviewed studies were only conducted in 10 out of 22 EMR countries included in the search. Iran $(n=35)$ was most represented in the included studies, followed by Saudi Arabia $(n=5)$ and Tunisia $(n=5)$, Jordan $(n=4)$, Pakistan $(n=2)$, and finally UAE, Palestine, Iraq, Oman, and Afghanistan ( $n=1$ each).

Overall, 1995 hospitals were examined in these studies; most of them located in Iran $(n=858)$, Saudi Arabia $(n=573)$, Tunisia $(n=266)$, UAE $(n=96)$, Jordan $(n=$ 72 ) and Afghanistan $(n=68)$. Out of 56 reviewed studies, 21 used DEA (37\%), 12 used Bayesian SFA (21\%), 10 used Pabon Lasso's model (18\%), and four studies used the Malmquist index (7.5\%). Moreover, four studies (7.5\%) used a hybrid approach by comparing DEA and Pabon Lasso's model. Finally, five studies (9\%) used other methods (the Cobb-Douglas Model, the Lean model, and efficiency and performance indicators).

Calculating efficiency requires input and output variables. In data analysis, the number of workforce, active beds, total costs, hospital size, medical equipment, technological capacity, and budget have been used as input variables (Fig. 2). Total outpatient visits, inpatient admissions and days, number of inpatients, emergency visits, number of surgeries, ratio of major surgeries to total surgeries, total number of medical interventions, BOR, BTR, average length of stay (ALS), number of ambulances, ratio of active beds to fixed beds, hoteling expense (bed-day costs) and employee expense total survival rate, number of discharged patients, number of imaging service users, and number of laboratory test users, were used as output variables (Fig. 3). The input and output selection depends on the objective of the study and efficiency measurement. It is reasonable to consider total costs on the input side; however, few studies have employed hospital hoteling and workforce 


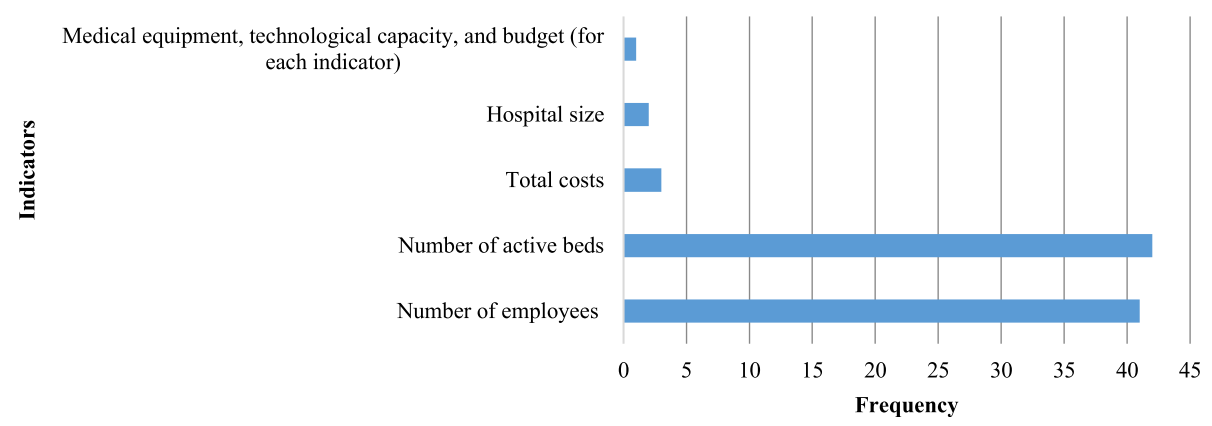

Fig. 2 Frequency of input variables used to measure hospital efficiency in EMR countries

expenses as output in their evaluation. For example, Hatam [15] used hoteling and workforce expenses and found that most cases had more workforce and hoteling expenses than the similar ones showing significant inefficiency.

Operational definitions for acronyms and terms of input and output measures are given below:

- Number of active beds: alternative term for 'available beds' [16].

- Number of beds or hospital size: "Hospital beds include all beds that are regularly maintained and staffed and are immediately available for use. They include beds in general hospitals, mental health, and substance abuse hospitals, and other specialty hospitals. Beds in nursing and residential care facilities are excluded" [17].

- Number of inpatient admissions: Mean number of hospital admissions in a certain hospital per year [16].

- Number of bed-days: "number of days during which a person is confined to a bed and in which the patient stays overnight in a hospital" [18].

- Bed occupancy rate (BOR): "The occupancy rate for curative (acute) care beds is calculated as the number of hospital bed-days related to curative care divided by the number of available curative care beds, multiplied by 365 ".

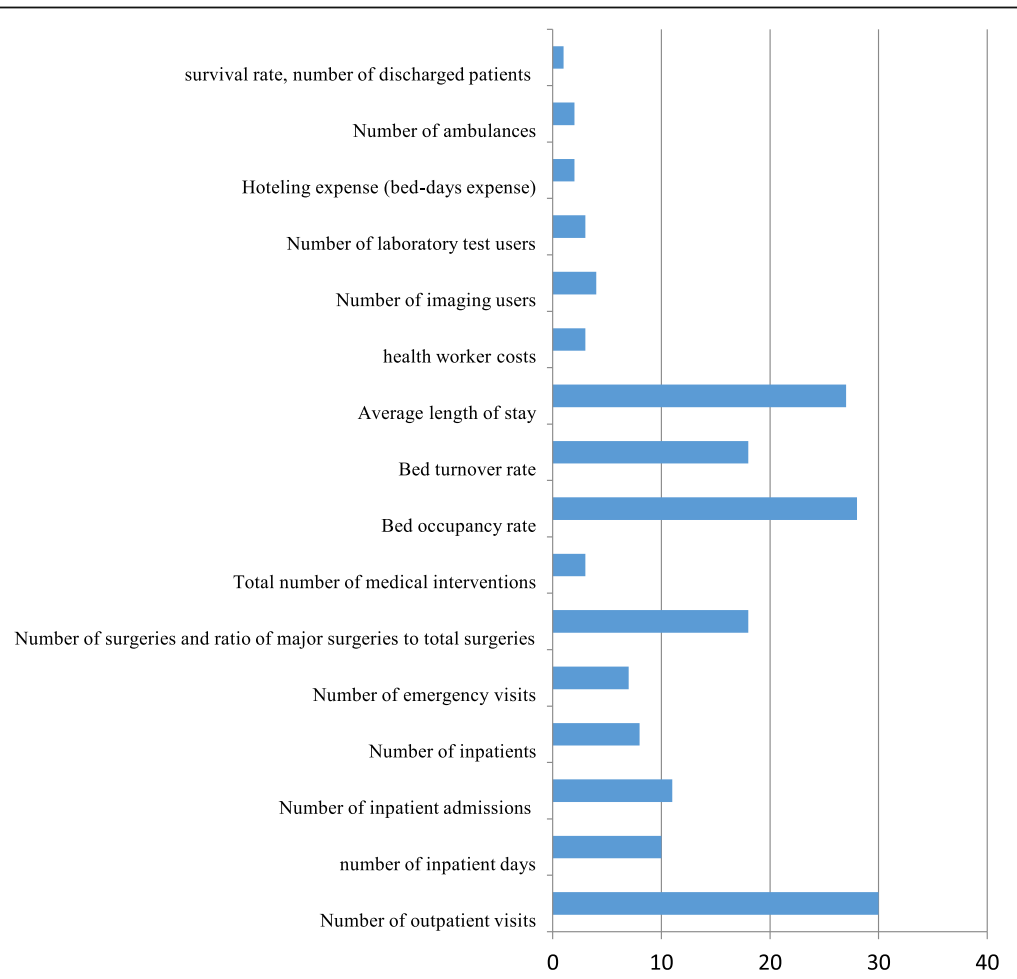

Fig. 3 Frequency of output variables used to measure hospital efficiency in EMR countries 
- Bed turnover rate (BTR): the number of times there is change of occupant for a bed during a given time period [17].

- Average length of stay (ALS): "Average length of stay refers to the average number of days that patients spend in hospital. It is generally measured by dividing the total number of days stayed by all inpatients during a year by the number of admissions or discharges. Day cases are excluded" [17].

- Day surgery: Day surgery is defined as the release of a patient who was admitted to a hospital for a planned surgical procedure and was discharged the same day [16].

Table 1 provides a summary of the studies reviewed, presenting the type and total number of hospitals examined, the methods used to calculate efficiency, inputs and outputs, and the source of inefficiency.

Various sources of hospital inefficiency were identified and divided into four themes, each with a set of subthemes: hospital products and services, hospital workforce, hospital services delivery, hospital system leakage (Table 2).

The most frequent sources of inefficiency in EMR hospitals are excess workforce, excess beds, and inappropriate hospital sizes. Helal et al. [66] investigated the effect of health reforms (privatization) on the efficiency of 270 hospitals in Saudi Arabia and reported a 0.90 average efficiency in 2006 and a 0.92 average efficiency in 2014. The average efficiency of one is considered the best level of performance. Despite a reduction in inputs, outputs increased by $2 \%$. Moreover, there was a $10.1 \%$ increase in the number of inpatients from 2006 to 2014. Therefore, reducing excess inputs such as excess workforce, excess beds or/and increasing outputs can be beneficial to hospitals. A 2013 analysis in Saudi Arabia showed that there was a reduction in the number of beds, doctors, nurses, and allied health workforce as inputs. Moreover, there was an increase in the number of inpatients, outpatients, the number of daily laboratory tests and the number daily of radiography services as outputs [39]. The most common strategies proposed in the included studies are: developing health policies for accurate recruitment planning, calculating the required number of beds for each community, and making proper use of hospital beds based on community needs.

\section{Discussion}

The purpose of this research was to examine the sources of hospital inefficiency and strategies available to increase hospital efficiency in the EMR. In recent years, there has been an increasing focus on hospital efficiency for health policymakers in developing countries. A total of 56 studies have been conducted on hospital efficiency in the EMR from January 1999 to May 2018. These studies have shown that hospital care is an economic activity requiring adequate funding and budgeting. As such, reducing inputs can improve performance and efficiency [56, 74].

The WHO Regional Office for the EMR classifies countries to there groups: high income countries (six countries), middle income countries (ten countries), and low income countries (six countries). The present research identified 56 articles on hospital efficiency in three highincome countries, five middle-income countries, and two low-income countries. General government expenditure allocated to health in the EMR countries remains between 2 and 16\%, a low figure. Regarding hospital service utilization, the overall average bed occupancy rate and length of stays were $60.7 \%$ and 4.12 days, respectively, in the Region in 2013. Only a few countries have welldefined and functioning referral networks between hospitals and primary health care facilities, or between hospitals at different levels. Hospitals do not serve geographically defined catchment areas based on national policy mandates. Most countries are entrenched in the historical model of public provision and financing, and there is a mix of funding patterns, including public sector funds (through central government budgets and national insurance funds) and out-of-pocket payments made directly by users. In most countries, there is misalignment between the distribution of hospital beds and high-technology equipment and population health needs [4]. Contextual challenges exist, such as security issues, internal conflict and political volatility in EMR countries, leading to economic problems influencing health policies, health system budgets, and health system efficiency as a result $[75,76]$.

Some health system challenges are common to all EMR countries: "limited capacity in $\mathrm{MoHs}$ for evidence-based policy analysis and formulation and strategic planning through better use of information in adequate capacity to legislate, regulate and enforce rules and regulations" or "most countries lack national medicines policy" [75]. Both this study and the WHO have reported similar findings.

The most common input variables used in these studies were workforces numbers and the number of beds, while the most common output variables were the total number of outpatient visits, admissions and inpatient days. A systematic review of new approaches to measure hospital performance in LMICs in 2015 [77] identified seven key performance indicators. These included total inpatient days; recurrent expenditure per inpatient day; ALS; infection prevention rate; BOR; inpatient days per technical workforce; and unit cost of outpatient care. Seven performance indicators were also identified for 


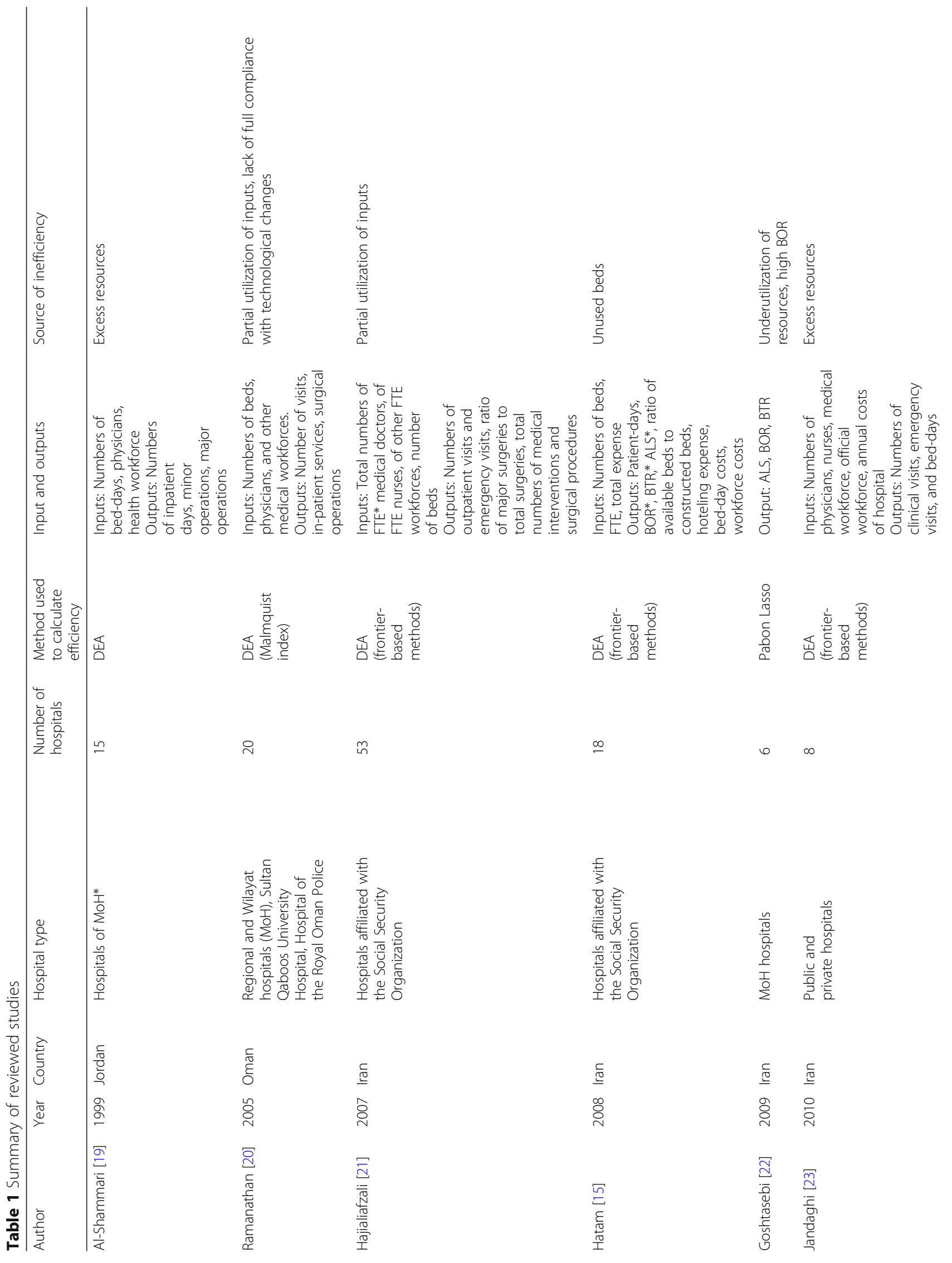




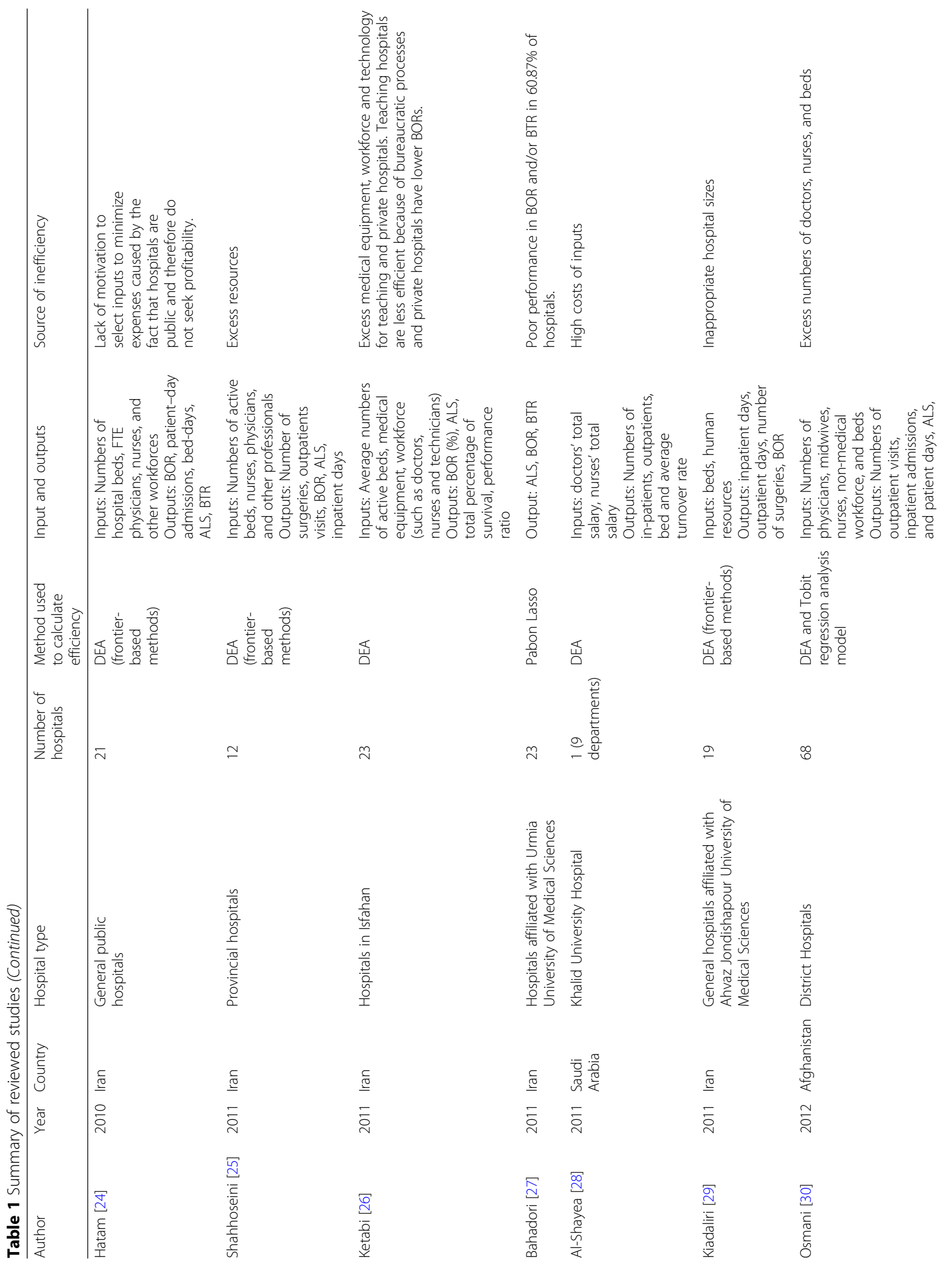




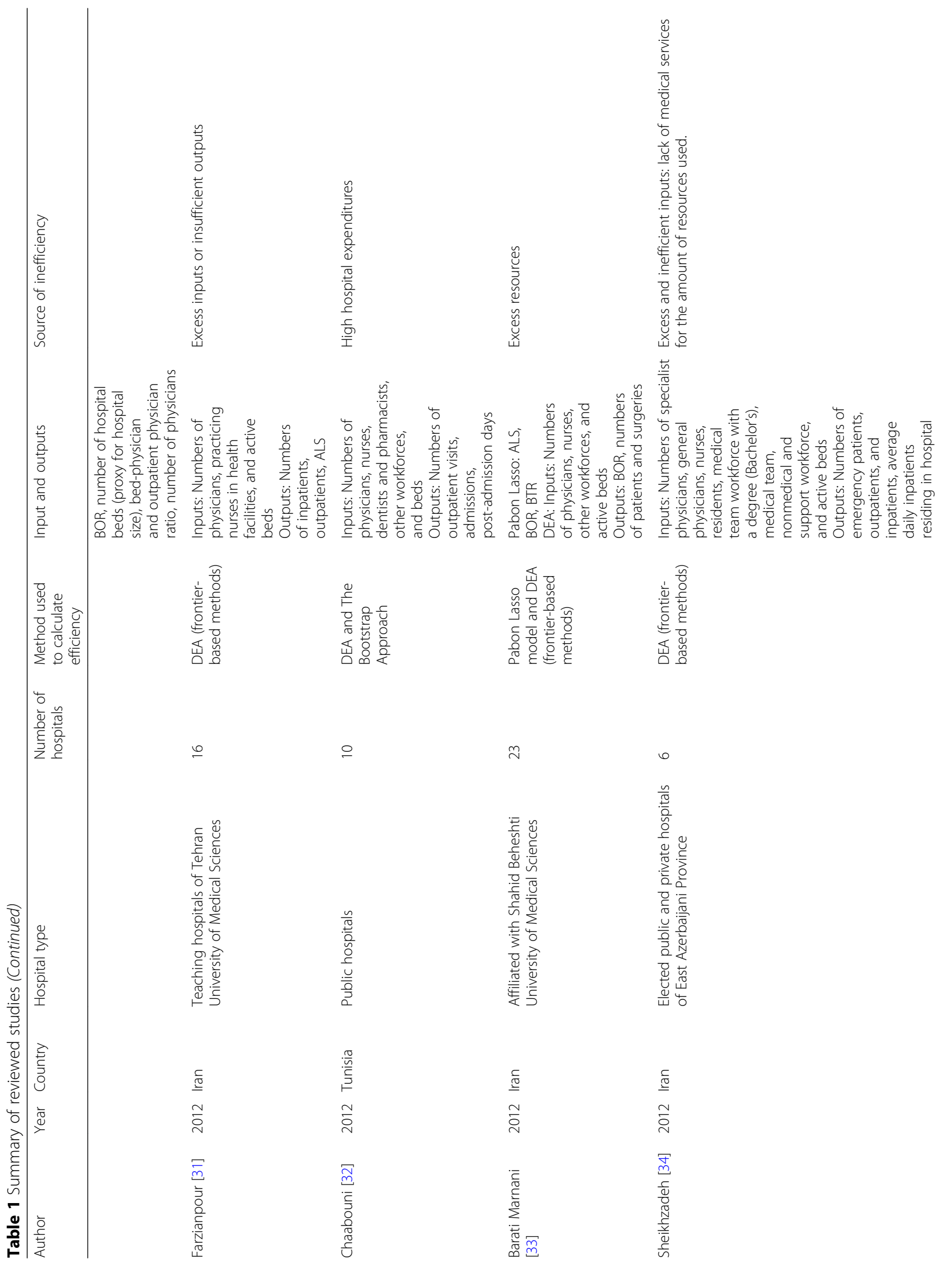




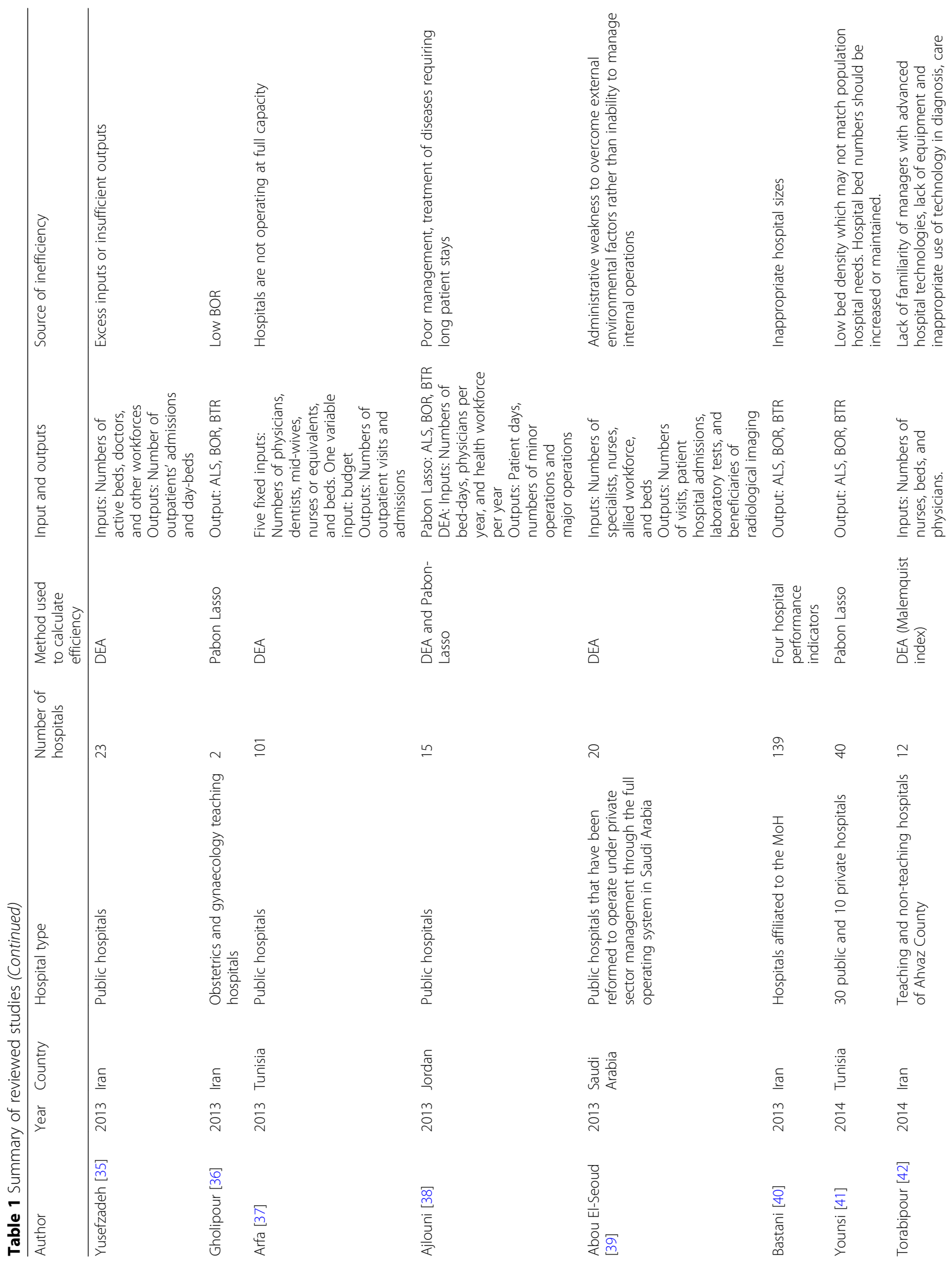




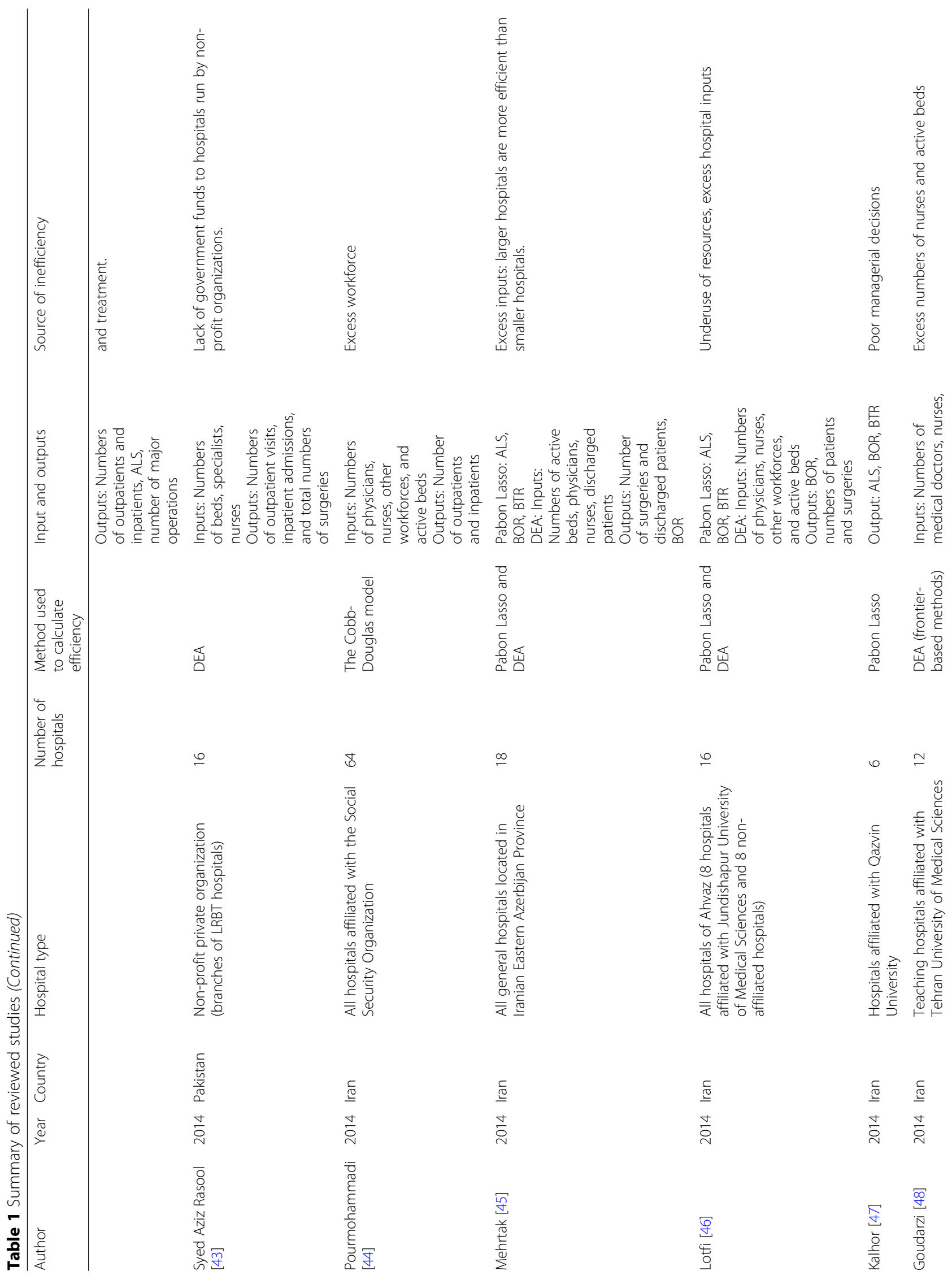




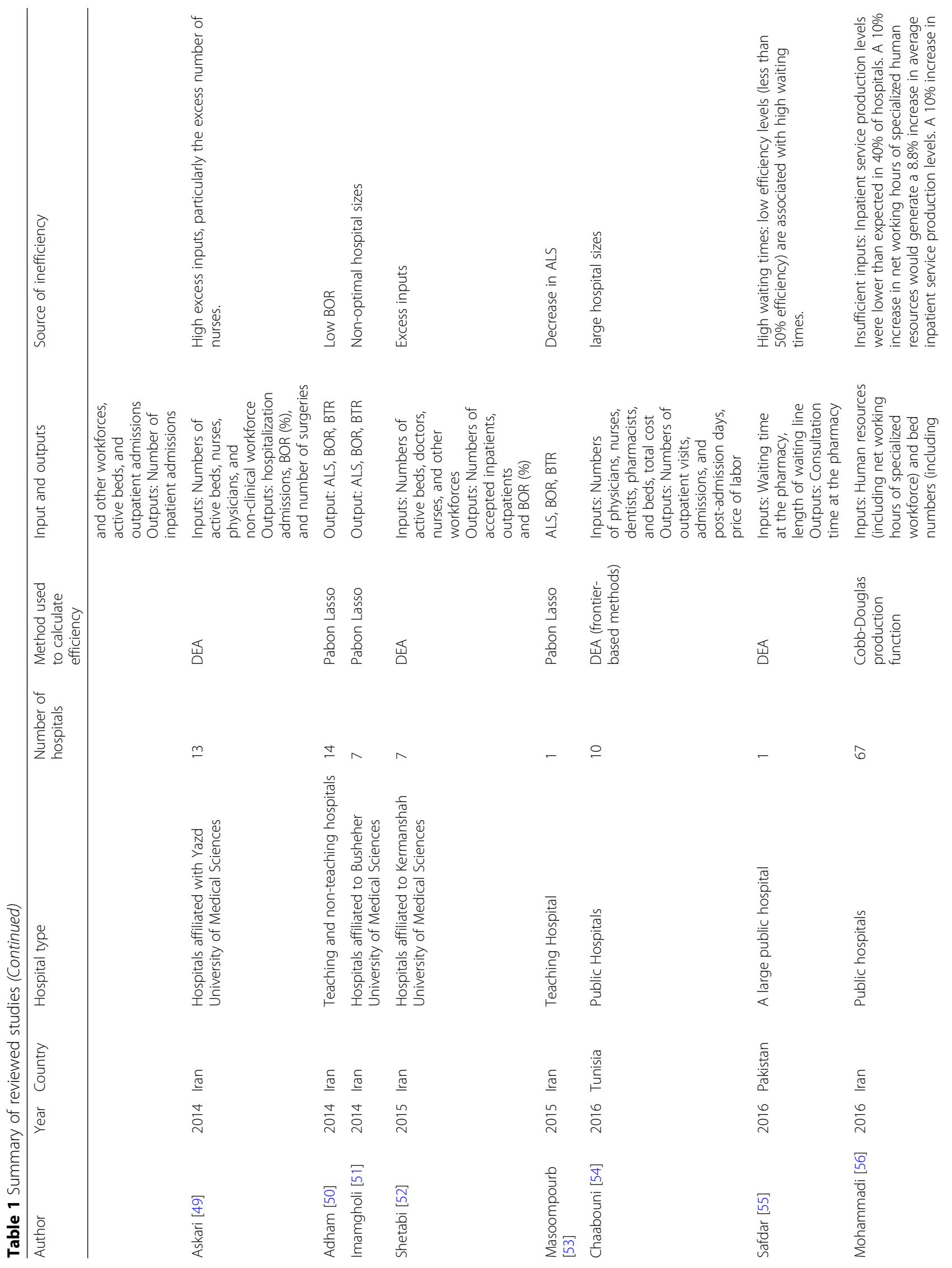




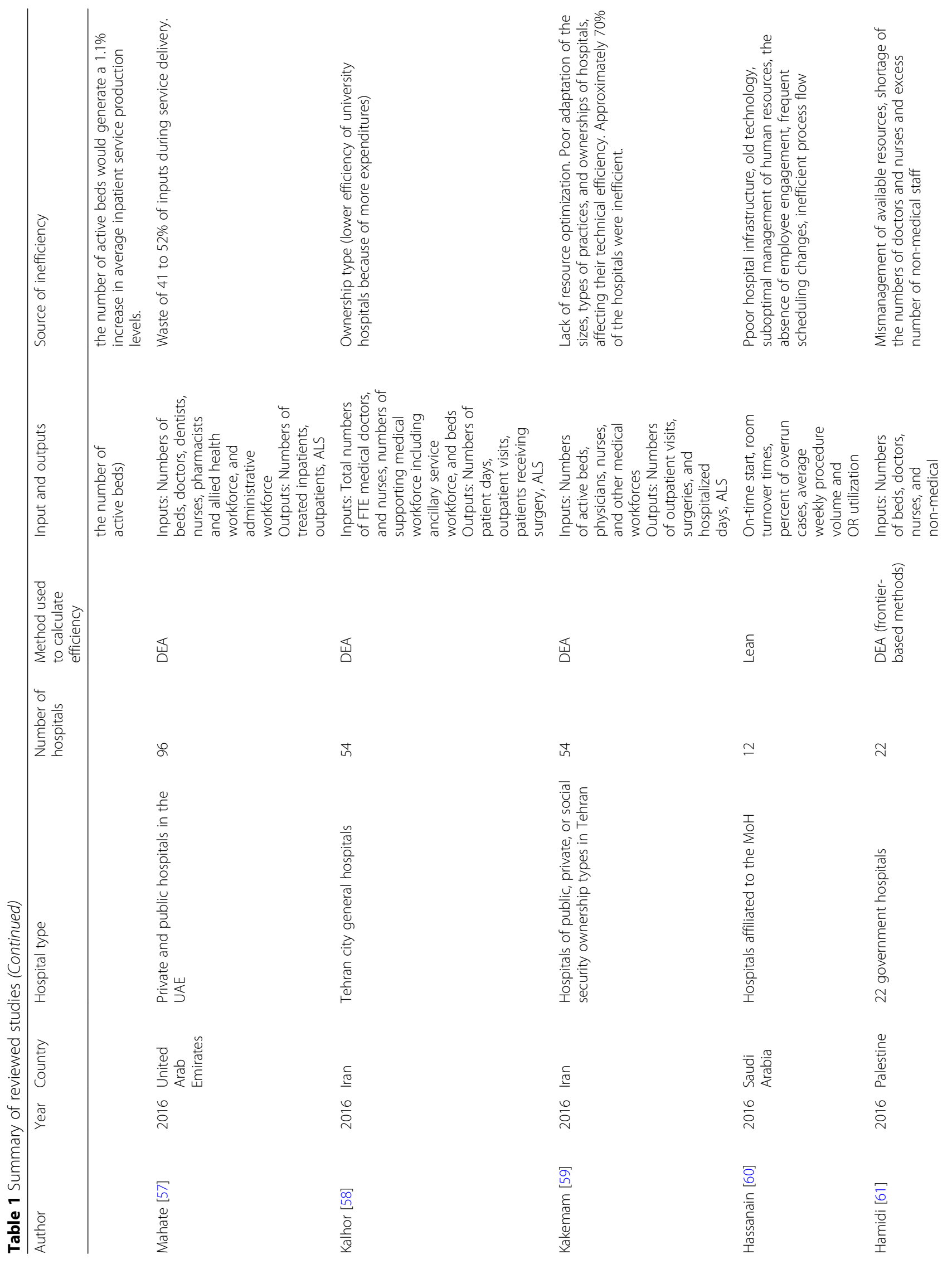




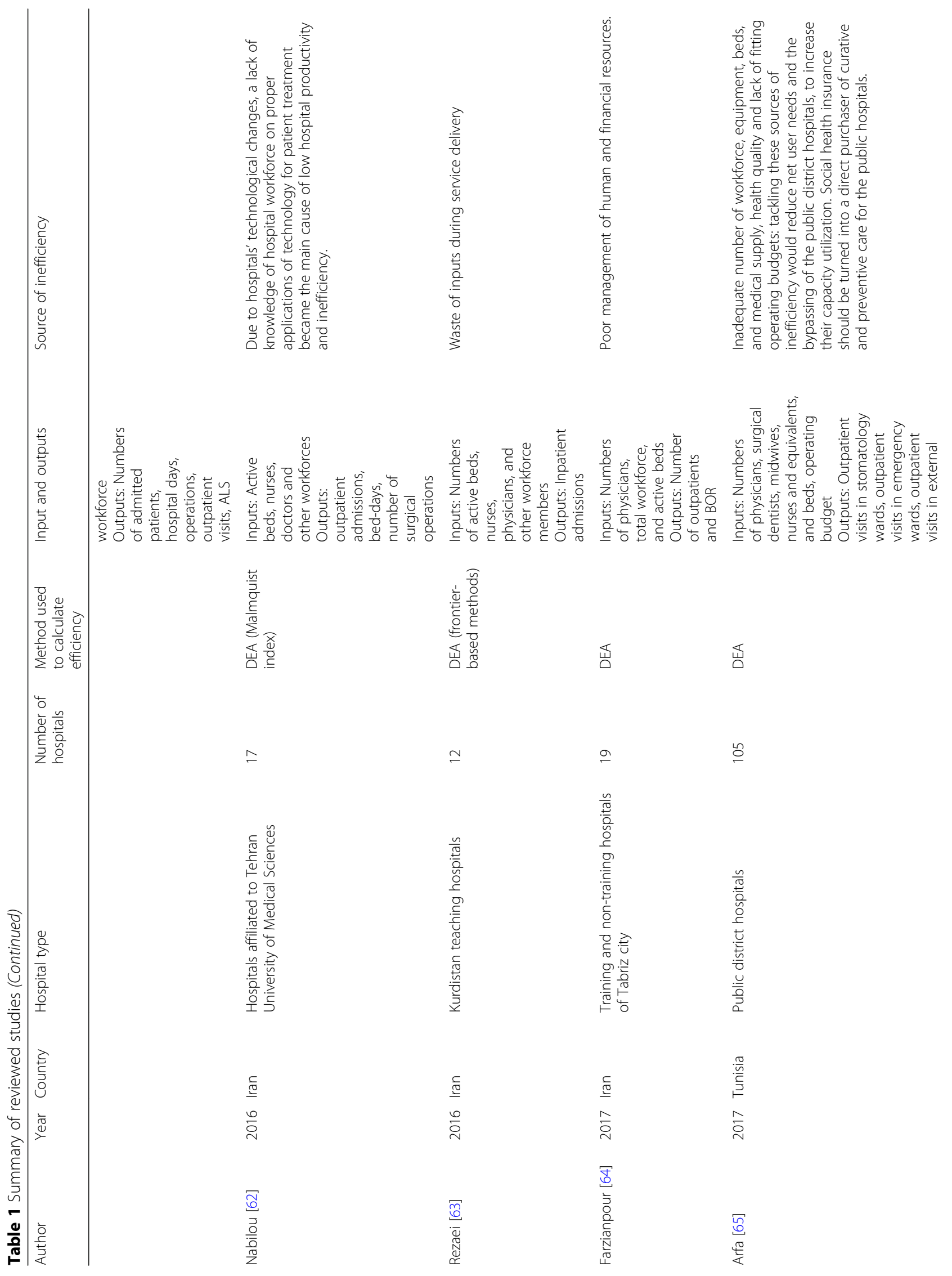




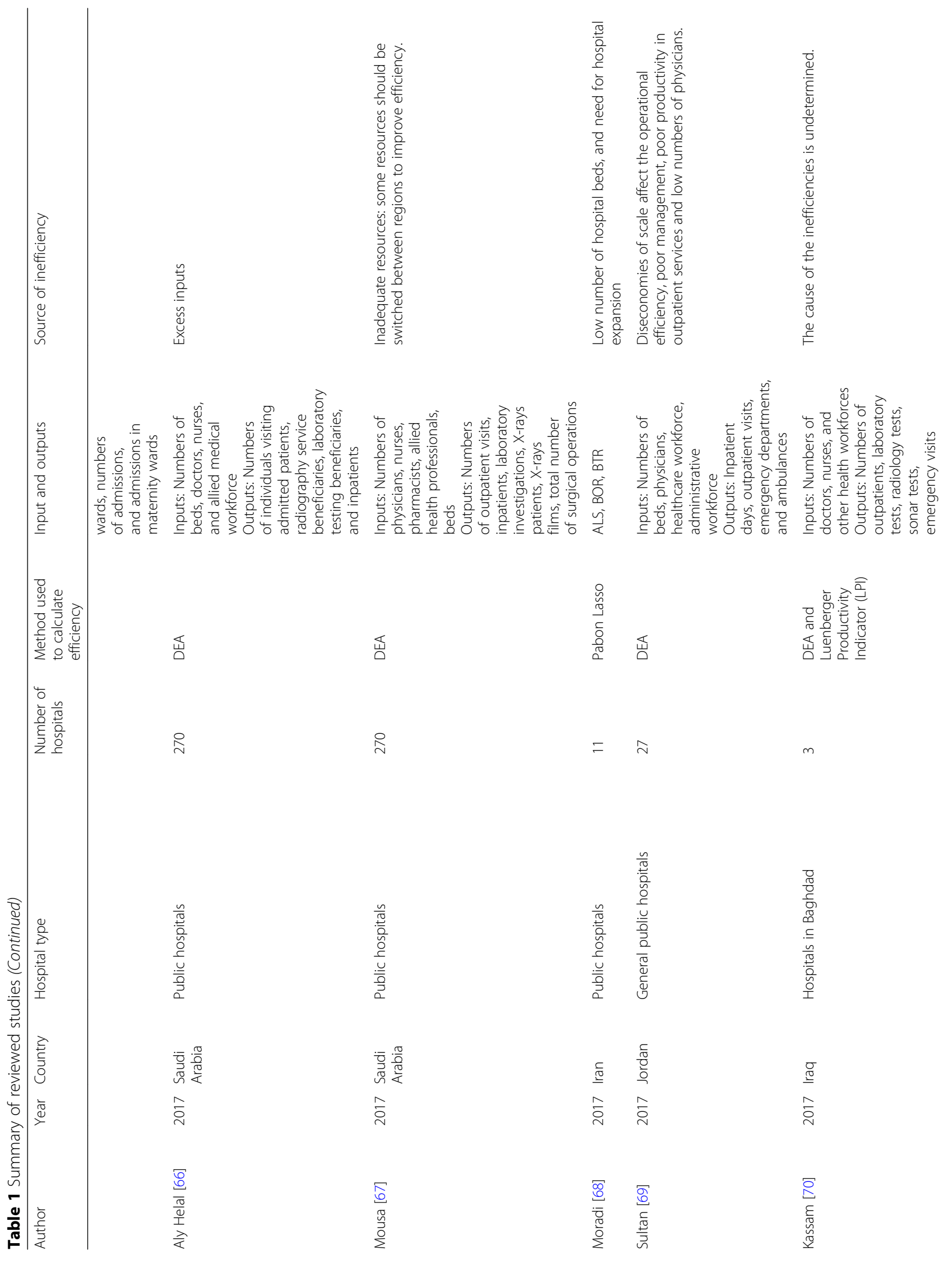




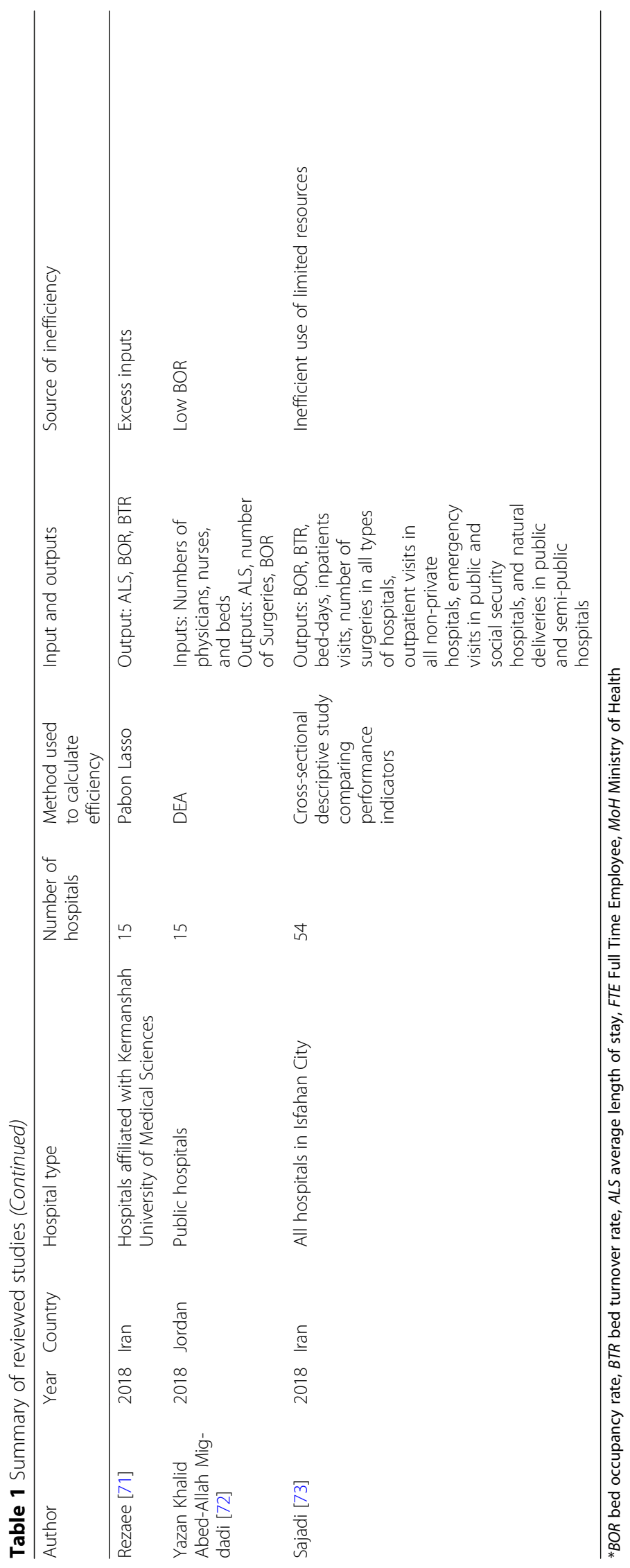


high-income countries (HICs): mortality rate from emergency heart attack admissions after 28 days; mortality rate from emergency surgery after 30 days; number of patients on waiting lists; infection rate of methicillinresistant Staphylococcus aureus per 10,000 bed-days; net profit; probability of workforce leaving within 12 months; and average healthcare commission rating [77].

On average, out-of-pocket payments differ between HICs and LMICs. In HICs, patients rarely pay directly for their care compared to LMICs where direct payment by patients is necessary due to lower insurance coverage. Furthermore, the mortality rate for non-elective admission is not the optimal output indicator for LMICs, as access to healthcare is a significant problem. These explain the differences in outputs between LMICs and HICs $[77,78]$.

The themes related to inefficiency extracted in this review, and the sources of inefficiency identified in the WHO report 2010 [11], highlight that studies have failed to address the issue of medical drugs. Using drug-related inputs and outputs can provide useful insights into drug-related sources of inefficiency in the EMR. For example, a study in Ethiopia used the cost of drug supply as input [79]. This can provide further insights into how to improve hospital efficiency.

In addition to excess workforce, excess beds and inappropriate hospital sizes, the inefficiency of hospitals in the EMR is also due to inappropriate workforce composition, lack of workforce motivation and inefficient use of health system inputs. According to a WHO report about National Health Accounts published in 2009, 15 to $25 \%$ of hospital inefficiency is related to workforce [80]. The workforce is at the core of the health system and accounts for almost half of the total health budget, in the form of wages and other payments [81]. The shortage of human resources is a major obstacle in implementing national healthcare plans, causing ineffective recruitment, inappropriate training, poor supervision, and suboptimal workforce distribution, which can further reduce efficiency [82]. Strategies to increase workforce efficiency focus on assessment and training based on needs, reviews of incentive policies, flexible contracts and performance-based payments [83].

Hospitals can result in lower efficiency if healthcare products and services are not optimal. Hospitals will face higher inputs against the specific output or lower outputs against the specific input. Excessive lengths of hospital stays, unnecessary admissions, and unnecessary referrals to specialists are examples of overuse of healthcare services. Reduced demand for hospital services and low BORs indicate underuse of available services [25-32]. A WHO report showed that suboptimal use of hospital resources, such as doctors, nurses, and beds, reduce demand for services and thus reduce hospital efficiency [82]. Optimal hospital management plays a vital role in optimizing healthcare services, improving hospital outcomes, and reducing costs [84-86]. Hospital managers and health policymakers can increase hospital efficiency and productivity through economies of scale. Strategies include optimizing hospital size, providing more products and services, and reducing ALS [38, 84-86].

Two of the principal sources of inefficiency in the EMR are inappropriate hospital sizes and excess numbers of active beds. These have been analyzed in studies conducted in countries outside the EMR, including in HICs [14, 21, 24-26, 33-35, 62]. These studies revealed the significant impact of hospital size and bed numbers on efficiency [87, 88]. The optimal number of active hospital beds typically lies between 200 and 300 beds. Generally, hospitals with less than 200 beds or more than 600 beds have higher costs [89]. According to international standards, a threshold BOR range between 84 and $85 \%$ indicates that use of hospital facilities and hospital resources are optimally efficient [90]. Therefore, optimizing hospital sizes and bed numbers can ensure that hospitals respond to population needs thus increasing efficiency. Indeed, it may be necessary for governments to build hospitals of a specific size, to take into account geographical considerations and difficulties accessing healthcare facilities.

The payment system has a vital role in improving hospital efficiency and productivity. In the EMR, payment systems are typically fee-for-service systems. In developed countries payments are often based on performance at clinical and organizational levels, increasing efficiency through performance incentives [91, 92]. Strategies to increase hospital efficiency include developing healthcare policies to implement appropriate payment systems, fair tariffs, and meticulous workforce recruitment plans, calculating required bed numbers for each community, making optimal use of hospital beds based on demand, and developing two-way electronic referral systems.

\section{Conclusion}

The results of this study have elucidated numerous sources of hospital inefficiency in the EMR. These sources should be addressed with targeted strategies, to improve hospital performance. Severe resource scarcity and increased costs of healthcare services, particularly in developing countries, require policymakers to ensure maximum use of available resources. Hospitals are highly complex, multidisciplinary social entities, whose performance can be improved through accurate, 
Table 2 Source of inefficiency in Eastern Mediterranean hospitals and strategies for improvement

\begin{tabular}{llll}
\hline Source of inefficiency & Common sources of inefficient performance & Proposed actions \\
\hline Hospital & overuse or supply of & - Inappropriate payment systems (fee-for-service payment & -Reform incentive and payment structures, developing \\
products & equipment, & mechanisms) & appropriate tariff and payment systems (e.g. use capitation or \\
and & investigations, and & - Misuse or inappropriate use of technology in patient & diagnosis-related group mechanism for reimbursement) \\
services & procedures & treatment and diagnosis like imaging and lab services due & -Raising workforce awareness and training workforce and \\
& & to lack of knowledge and skills of health professional and & managers about new information systems and technologies \\
& lack of adopted evidenced-based guidelines. & -Raising workforce awareness of energy management \\
& - Overuse or oversupply of equipment & through frequent training \\
& - Lack of or defective hospital equipment & -Develop and implement clinical guidelines \\
& - Poor standards for use of technologies &
\end{tabular}

Hospital inappropriate or costly - Lack of or failure to use specialized managers in hospital workforce workforce mix

Hospital

$\begin{array}{ll}\text { workforce mix } & \text { administration } \\ & \text { Suboptimal use of workforce capabilities, including those of } \\ & \text { physicians, nurses, paramedics, and support workforce, } \\ & \text { resulting in excess workforce in some departments } \\ \text { - Inadequate management of hospital resources like } & \text { workforce }\end{array}$

unmotivated workforce

- Lack of motivation due to high workload

- Lack of workforce motivation in the public sector because of inadequate salaries

inappropriate hospital admissions and length of stay
- Inappropriate ALS*, unnecessary admissions, low BORs* and unnecessary referrals to specialists due to inadequate knowledge and training of workforce about best practice.
-Recruiting workforce based on hospital needs (both in terms of numbers and specialties required)

-Preventing the recruitment and maintenance of specialist workforce who are not significantly relevant to hospital and patient needs.

-Using work measurement and time management techniques for optimal use of the workforce with respect to the volume of hospital operations

-Introducing performance-based payments

-Use appropriate incentive, reward and appraisal systems

-Developing and implementing policies to accelerate admission and discharge processes and increase the quality of services

-Developing strategies to reduce ALS*, including full-time presence of physicians and modification of hospital funding policies

-Establishing a two-way electronic referral system, to provide physicians with feedback

-Effective marketing using appropriate customer information, and improving communication and customer loyalty

inappropriate hospital size (low use of infrastructure)

- Inefficient hospital size, lack of scale efficiency and too many hospitals and inpatient beds in some areas, not enough in others

- Suboptimal use of available capacities such as infrastructure and active beds, resulting in excess beds in some departments (lack of planning)

-Modifying hospital size: selecting an efficient size and preventing hospital overdevelopment. if inefficient (downsizing or merging hospitals)

-Making optimal use of hospital beds based on community needs.

-Use of cost analysis and DEA model and other efficiency measurement models for incorporate inputs and output estimation into hospital planning.

-Improving workforce, equipment, and beds based on evidence

-Designing a basic framework for optimal resource allocation by health policymakers

-Diversifying the outputs required for compensating hospital inefficiency

-Redistributing hospital resources among regions

-Training to raise knowledge about efficient admission practice

-Designing on-the-job training courses tailored to workforce roles.

suboptimal quality of

- Poor care management skills of physicians and other workforces.

- Inadequate managerial skills and lack of training for hospital managers.

- Inadequate skills and training of the hospital workforce. nappropriate suboptimal allocation of funds among hospitals and unclear resource allocation guidance.

- Hospital reliance on public funds and budgets, and lack of competition with other organizations.
-Using experienced and well-educated managers with management or healthcare management degrees, performance evaluation of hospital managers and provide feedback -Introducing managers to management techniques and methods of economic analysis

-Improve hygiene standards in hospitals; provide more continuity of care; undertake more clinical audits; monitor hospital performance

-Modifying hospital budget structures -Improve regulation/governance, including strong sanction mechanisms; assess transparency/vulnerability to corruption; undertake public spending tracking surveys; promote codes of conduct 
effective, and timely planning, organization, leadership, and management. Efficiency depends on multiple factors. As such, using various methods to measure hospital efficiency can be an effective strategy for managers and policymakers. Needs-based assessments and training, reviews of incentive policies, flexible contracts, performance-based payments, optimal hospital sizes based on community needs, increased resource availability and preservation of hospital social functions are crucial to increasing hospital efficiency.

\section{Supplementary information}

Supplementary information accompanies this paper at https://doi.org/10. 1186/s12913-019-4701-1.

Additional file 1. Search strategy in Medline via PubMed.

\section{Abbreviations}

ALS: Average length of stay; BOR: Bed occupancy rate; BTR: Bed turnover rate; DEA: Data Envelopment Analysis; EMR: Eastern Mediterranean Region; FTE: Full Time Employee; HICs: High-income countries; LMICs: Low- and middle-income countries; MoH: Ministry of Health; SFA: Stochastic Frontier Analysis; WHO: World Health Organization

\section{Acknowledgements}

Not applicable.

\section{Authors' contributions}

$M A$ and $H R$ designed the research; MA and PI conducted it; MA and PI extracted the data; and MA, HR, VDB, and PI wrote the paper. MA had primary responsibility for final content. All authors read and approved the final manuscript.

\section{Funding}

This study had no funding.

\section{Availability of data and materials}

Not applicable.

\section{Ethics approval and consent to participate}

Not applicable.

\section{Consent for publication}

Not applicable.

\section{Competing interests}

The authors declare that they have no competing interests.

\section{Author details}

${ }^{1}$ Department of Health Service Management, School of Health Management and Information Sciences, Iran University of Medical Sciences, Tehran, Iran. ${ }^{2}$ School of Public Health, Zabol University of Medical Sciences, Zabol, Iran. ${ }^{3}$ World Health Organization, Regional Office for the Eastern Mediterranean, Monazamet El Seha El Alamia Street, Extension of Abdel Razak El Sanhouri Street, Nasr City, Cairo, Egypt.

Received: 14 May 2019 Accepted: 31 October 2019

Published online: 12 November 2019

\section{References}

1. Velasco-Garrido M, Busse R. Health technology assessment: an introduction to objectives, role of evidence, and structure in Europe. InHealth technology assessment: an introduction to objectives, role of evidence, and structure in Europe 2005. Copenhagen: WHO Regional Office for Europe; 2002. http://www.euro.who.int/observatory/ Publications/20020527_16. Accessed 20 Jan 2019
2. Mosadeghrad AM, Esfahani P, Nikafshar M. Hospitals' efficiency in Iran: a systematic review and meta-analysis of two decades of research. J Payavard Salamat. 2017;11(3):318-31.

3. Parker D, Newbrander W. Tackling wastage and inefficiency in the health sector; 1994.

4. Eastern Mediterranean Regional Office, World Health Organization. Introducing the framework for action for the hospital sector in the Eastern Mediterranean Region. Regional Committee for the Eastern Mediterranean. EM/RC66/5. 2019. http://applications.emro.who.int/docs/RC_Technical_ Papers_2019_5_en.pdf?ua=1. Accessed 27 Sept 2019.

5. World Health Organization. Improving hospital performance in the Eastern Mediterranean Region, 2009.

6. Abdullatif AA. Hospital care in WHO Eastern Mediterranean Region; an agenda for change. In: International Hospital Federation Reference Book 2005/2006. Ferney Voltaire: International Hospital Federation; 2005.

7. Pourreza A, Alipour V, Arabloo J, Bayati M, Ahadinezhad B. Health production and determinants of health systems performance in $\mathrm{WHO}$ Eastern Mediterranean Region. East Mediterr Health J. 2017;23(5):368-74.

8. Farrell MJ. The measurement of productive efficiency. J R Stat Soc Series A (General). 1957. https://doi.org/10.2307/2343100.

9. Charnes A, Cooper WW, Rhodes E. Measuring the efficiency of decision making units. Eur J Oper Res. 1978. https://doi.org/10.1016/03772217(78)90138-8.

10. Aigner D, Lovell CK, Schmidt P. Formulation and estimation of stochastic frontier production function models. J Econom. 1977. https://doi.org/10. 1016/0304-4076(77)90052-5.

11. Pabon LH. Evaluating hospital performance through simultaneous application of several indicators; 1986

12. Chisholm D, Evans DB. Improving health system efficiency as a means of moving towards universal coverage. World health report 2010 background paper, no. 28. http://www.who.int/healthsystems/topics/financing/ healthreport/whr_background/en. Accessed 17 July 2018.

13. Liberati A, Altman DG, Tetzlaff J, Mulrow C, Gotzsche PC, loannidis JP, et al. The PRISMA statement for reporting systematic reviews and meta-analyses of studies that evaluate healthcare interventions: explanation and elaboration. BMJ. 2009. https://doi.org/10.1136/bmj.b2700.

14. Mitton C, Adair CE, McKenzie E, Patten SB, Perry BW. Knowledge transfer and exchange: review and synthesis of the literature. Milbank Q. 2007. https://doi.org/10.1111/j.1468-0009.2007.00506.x.

15. Hatam N. The role of Data Envelopment Analysis (DEA) pattern in the efficiency of social security hospitals in Iran. Iran Red Crescent Med J. 2008; 10(3):211-7.

16. World Health Organization (WHO). 2015 Global Reference List of 100 Core Health Indicators. 2015. http://apps.who.int/iris/bitstream/10665/173589/1/ WHO_HIS_HSI_2015.3_eng.pdf.

17. OECD. Health at a glance: Europe 2018: Organization for economic. Paris: OECD; 2018

18. OECD Health Data 2001. A comparative analysis of 30 countries; data sources, definitions and methods. Paris: OECD; 2001

19. Al-Shammari M. A multi-criteria data envelopment analysis model for measuring the productive efficiency of hospitals. Int J Oper Prod Man. 1999;19(9):879-91.

20. Ramanathan R. Operations assessment of hospitals in the Sultanate of Oman. Int J Oper Prod Man. 2005. https://doi.org/10.1108/ 01443570510572231

21. Hajialiafzali H, Moss J, Mahmood M. Efficiency measurement for hospitals owned by the Iranian social security organisation. J Med Syst. 2007. https:// doi.org/10.1007/s10916-007-9051-6.

22. Goshtasebi A, Vahdaninia M, Gorgipour R, Samanpour A, Maftoon F, Farzadi $F$, et al. Assessing hospital performance by the Pabon lasso model. Iran J Public Health. 2009;38(2):119-24.

23. Jandaghi $\mathrm{G}$, Matin $\mathrm{HZ}$, Doremami M, Aghaziyarati M. Efficiency evaluation of Qom public and private hospitals using data envelopment analysis. Eur J Econ Finance Adm Sci. 2010;22(2):83-91.

24. Hatam N, Moslehi S, Askarian M, Shokrpour N, Keshtkaran A, Abbasi M. The efficiency of general public hospitals in Fars Province, Southern Iran. Iran Red Crescent Med J. 2010;12(2):138.

25. Shahhoseini R, Tofighi S, Jaafaripooyan E, Safiaryan R. Efficiency measurement in developing countries: application of data envelopment analysis for Iranian hospitals. Health Serv Manag Res. 2011. https://doi.org/ 10.1258/hsmr.2010.010017. 
26. Ketabi S. Efficiency measurement of cardiac care units of Isfahan hospitals in Iran. J Med Syst. 2011. https://doi.org/10.1007/s10916-009-9351-0.

27. Mohammadkarim B, Jamil S, Pejman H, Seyyed MH, Mostafa N. Combining multiple indicators to assess hospital performance in Iran using the Pabon Lasso model. Australas Med J. 2011. https://doi.org/10. 4066/AMJ.2011.620.

28. Al-Shayea AM. Measuring hospital's units efficiency: a data envelopment analysis approach. Int J Eng Technol. 2011;11(6):7-19.

29. Ahmadkiadaliri A, Haghparast-Bidgoli H, Zarei A. Measuring efficiency of general hospitals in the south of Iran. World Appl Sci J. 2011;13(6):1310-6.

30. Osmani AR. Technical efficiency of district hospitals in Afghanistan: a data envelopment analysis approach: Chulalongkorn University; 2012.

31. Farzianpour F, Hosseini S, Amali T, Hosseini S, Hosseini SS. The evaluation of relative efficiency of teaching hospitals. Am J Appl Sci. 2012;9(3):392.

32. Chaabouni S, Abednnadher C. Efficiency of public hospitals in Tunisia: a DEA with bootstrap application. Int J Behav Healthc Res. 2012. https://doi.org/10. 1504/IJBHR.2012.051380.

33. Marnani AB, Sadeghifar J, Pourmohammadi K, Mostafaie D, Abolhalaj M, Bastani P. Performance assessment indicators: how DEA and Pabon lasso describe Iranian hospitals' performance. Health Med. 2012;6(7):791-6.

34. Sheikhzadeh Y, Roudsari AV, Vahidi RG, Emrouznejad A, Dastgiri S. Public and private hospital services reform using data envelopment analysis to measure technical, scale, allocative, and cost efficiencies. Health Promot Perspect. 2012;2(1):28.

35. Yusefzadeh H, Ghaderi H, Bagherzade R, Barouni M. The efficiency and budgeting of public hospitals: case study of Iran. Iran Red Crescent Med J. 2013;15(5):393

36. Gholipour K, Delgoshai B, Masudi-Asl I, Hajinabi K, lezadi S. Comparing performance of Tabriz obstetrics and gynaecology hospitals managed as autonomous and budgetary units using Pabon Lasso method. Australas Med J. 2013. https://doi.org/10.4066/AMJ.2013.1903.

37. Arfa C, Sabri B. Appraising the efficiency of public hospitals in Tunisia. Future Healthc. 2013. https://doi.org/10.1007/s10754-013-9123-8.

38. Ajlouni M, Zyoud A, Jaber B, Shaheen H, Al-Natour M, Anshasi RJ. The relative efficiency of Jordanian public hospitals using data envelopment analysis and Pabon Lasso diagram. Glob J Bus Res. 2013;7(2):59-72.

39. Abouel-Seoud M. Measuring efficiency of reformed public hospitals in Saudi Arabia: an application of data envelopment analysis. Int J Econ Manag Sci. 2013;2(9):44-53.

40. Bastani P, Vatankhah S, Salehi M. Performance ratio analysis: a national study on Iranian hospitals affiliated to ministry of health and medical education. Iran J Public Health. 2013;42(8):876.

41. Younsi M. Performance of Tunisian public hospitals: a comparative assessment using the Pabon Lasso model. Hosp Res. 2014;3(4):159-66.

42. Torabipour A, Najarzadeh M, Mohammad A, Farzianpour F, Ghasemzadeh R. Hospitals productivity measurement using data envelopment analysis technique. Iran J Public Health. 2014;43(11):1576.

43. Rasool SA, Saboor A, Raashid M. Measuring efficiency of hospitals by DEA: an empirical evidence from Pakistan. Int Public Health J. 2014. https://doi. org/10.11591/.v3i2.4684.

44. Pourmohammadi K, Hatam N, Bastani P, Lotfi F. Estimating production function: a tool for Hospital Resource Management. Shiraz E Med J. 2014. https://doi.org/10.17795/semj23068

45. Mehrtak M, Yusefzadeh H, Jaafaripooyan E. Pabon Lasso and data envelopment analysis: a complementary approach to hospital performance measurement. Glob J Health Sci. 2014. https://doi.org/10.5539/gjhs. v6n4p107.

46. Lotfi F, Kalhor R, Bastani P, Zadeh NS, Eslamian M, Dehghani MR, et al. Various indicators for the assessment of hospitals' performance status: differences and similarities. Iran Red Crescent Med J. 2014;16(4):e12950.

47. Kalhor R, Salehi A, Keshavarz A, Bastani P, Orojloo P. Assessing hospital performance in Iran using the Pabon Lasso model. Asia Pac J Health Manage. 2014;9(2):77

48. Goudarzi R, Pourreza A, Shokoohi M, Askari R, Mahdavi M, Moghri J. Technical efficiency of teaching hospitals in Iran: the use of stochastic frontier analysis, 1999-2011. Int J Health Policy Manag. 2014;3(2):91. https:// doi.org/10.15171/ijhpm.2014.66

49. Askari R, Farzianpour F, Goudarzi R, Shafii M, Sojaei S. Efficiency evaluation of hospitals affiliated with Yazd University of Medical Sciences using quantitative approach of data envelopment analysis in the year 2001 to 2011. Pensee J. 2014;76:416-25.
50. Adham D, Issac B, Sadeghi G, Mohammad P, Hossein A, Salarkhah E. Contemporary use of hospital efficiency indicators to evaluate hospital performance using the Pabon Lasso model. Eur J Bus Soc Sci. 2014;3(2):1-8.

51. Imamgholi S, Khatami Firouzabadi SMA, Goharinezhad S, Fadaei Dehcheshmeh N, Heidarinejad A, Azmal M. Assessing the efficiency of hospitals by using Pabon lasso graphic model. J Res Health. 2014;4(4):890-7.

52. Shetabi HR, Mirbahari SQ, Nasiripour AA, Safi Keykale M, Mohammadi H, Esfandnia A, Safari S, Kazemi M, Mohammadi M. Evluating technical efficiency of Kermanshah city universities by means of data envelopment analysis model. Res J Med Sci. 2015. https://doi.org/10. 3923/rjmsci.2015.53.57.

53. Masoompour SM, Petramfar P, Farhadi P, Mahdaviazad H. Five-year trend analysis of capacity utilization measures in a teaching hospital 2008-2012. Shiraz E-Med J. 2015. https://doi.org/10.17795/semj21176.

54. Chaabouni S, Abednnadher C. Cost efficiency of Tunisian public hospitals: a Bayesian comparison of random and fixed frontier models. J Knowl Econ. 2016. https://doi.org/10.1007/s13132-015-0245-8.

55. Safdar KA, Emrouznejad A, Dey PK. Assessing the queuing process using data envelopment analysis: an application in health centres. J Med Syst. 2016. https://doi.org/10.1007/s10916-015-0393-1.

56. Mohammadi H, Meskarpour-Amiri M. Estimation production function of inpatient services and input productivity: a cross-sectional study of Iran selected public hospitals. Hosp Pract Res. 2016;1(3):91-3.

57. Mahate A, Hamidi S. Frontier efficiency of hospitals in United Arab Emirates: an application of data envelopment analysis. J Hosp Adm. 2015. https://doi. org/10.5430/jha.v5n1p7.

58. Kalhor R, Amini S, Sokhanvar M, Lotfi F, Sharifi M, Kakemam E. Factors affecting the technical efficiency of general hospitals in Iran: data envelopment analysis. J Egypt Public Health Assoc. 2016. https://doi.org/10. 1097/01.EPX.0000480717.13696.3c.

59. Kakeman E, Forushani AR, Dargahi H. Technical efficiency of hospitals in Tehran. Iran Iran J Public Health. 2016:45(4):494.

60. Hassanain $M$, Zamakhshary $M$, Farhat G, Al BA. Use of lean methodology to improve operating room efficiency in hospitals across the Kingdom of Saud Arabia. Int J Health Plann Manag. 2017. https://doi.org/10.1002/hpm.2334.

61. Hamidi S. Measuring efficiency of governmental hospitals in Palestine using stochastic frontier analysis. Cost Eff Resour Alloc. 2016. https://doi.org/10. 1186/s12962-016-0052-5

62. Nabilou B, Yusefzadeh H, Rezapour A, Azar FEF, Safi PS, Asiabar AS, et al. The productivity and its barriers in public hospitals: case study of Iran. Med J Islam Repub Iran. 2016;30:316.

63. Rezaei S, Zandian H, Baniasadi A, Moghadam TZ, Delavari S, Delavari S. Measuring the efficiency of a hospital based on the econometric Stochastic Frontier Analysis (SFA) method. Electron Physician. 2016. https://doi.org/10. 19082/2025.

64. Farzianpour F, Emami AH, Foroushani AR, Ghiasi A. Determining the technical efficiency of hospitals in Tabriz City using data envelopment analysis for 2013-2014. Glob J Health Sci. 2016. https://doi.org/10.5539/gjhs. v9n5p42.

65. Arfa C, Leleu H, Goaied M, van Mosseveld C. Measuring the capacity utilization of public district hospitals in tunisia: using dual data envelopment analysis approach. Int J Health Policy Manag. 2016. https://doi. org/10.15171/ijhpm.2016.66.

66. Helal SMA, Elimam HA. Measuring the efficiency of health services areas in Kingdom of Saudi Arabia using data envelopment analysis (DEA): a comparative study between the years 2014 and 2006. Int J Health Care Finance Econ. 2017. https://doi.org/10.5539/ijef.v9n4p172.

67. Mousa W, Aldehayyat JS. Regional efficiency of healthcare services in Saudi Arabia. Middle East Dev J. 2018. https://doi.org/10.1080/17938120.2018. 1443607.

68. Moradi G, Piroozi B, Safari H, Nasab NE, Bolbanabad AM, Yari A. Assessment of the efficiency of hospitals before and after the implementation of health sector evolution plan in Iran based on Pabon Lasso model. Iran J Public Health. 2017:46(3):389.

69. Sultan WI, Crispim J. Evaluating the productive efficiency of Jordanian public hospitals. Int J Bus Manage. 2016. https://doi.org/10.5539/ijbm. v12n1p68.

70. Ali AM, Kassam A. Efficiency analysis of healthcare sector. Eng Technol J. 2017;35(5 Part (A) Engineering):509-15.

71. Rezaei S, Hajizadeh M, Bazyar M, Kazemi Karyani A, Jahani B, Karami MB. The impact of health sector evolution plan on the performance of hospitals in 
Iran: evidence from the Pabon Lasso model. Int J Health Gov. 2018. https:// doi.org/10.1108/JHG-09-2017-0046.

72. Migdadi YKA-A, Al-Momani HSM. The operational determinants of hospitals' inpatients departments efficiency in Jordan. Int J Oper Res. 2018;32(1):1-23. https://doi.org/10.1504/JOR.2018.091199.

73. Sajadi HS, Sajadi ZS, Sajadi FA, Hadi M, Zahmatkesh M. The comparison of hospitals' performance indicators before and after the Iran's hospital care transformations plan. J Educ Health Promot. 2017. https://doi.org/10.4103/ jehp.jehp_134_16.

74. Goudarzi R, RjabiGilan N, Ghasemi SR, Reshadat S, Askari R, Ahmadian M Efficiency measurement using econometric stochastic frontier analysis (SFA) method, case study: hospitals of Kermanshah University of Medical Sciences. J Kermanshah Univ Med Sci. 2014;17(10):666-72.

75. Eastern Mediterranean Regional Office, World Health Organization. Health systems in the Eastern Mediterranean Region: situation, challenges and gaps. High Level Expert Meetingon Health Priorities in the Eastern Mediterranean Region1-2March 2012. RDO/WP/12.5. 2012.

76. Blair I, Grivna M, Sharif AA. The "Arab World" is not a useful concept when addressing challenges to public health, public health education, and research in the Middle East. Front Public Health. 2014. https://doi.org/10. 3389/fpubh.2014.00030.

77. Adhikari SR, Sapkota VP, Supakankunti S. A new approach of measuring hospital performance for low- and middle-income countries. J Korean Med Sci. 2015. https://doi.org/10.3346/jkms.2015.30.S2.S143.

78. Waheb Y, Kamel L, Mena R. Cost analysis and efficiency indicators for health care: report number 3, summary output for El Gamhuria General Hospital, 1993-1994; 1997.

79. Ali M, Debela M, Bamud T. Technical efficiency of selected hospitals in Eastern Ethiopia. Health Econ Rev. 2017. https://doi.org/10.1186/s13561-017-0161-7.

80. World Health Organization (WHO). National Health Accounts database. Geneva: WHO; 2009.

81. Hernandez P, Dräger S, Evans DB, Tan-Torres Edejer T, Dal Poz MR Measuring expenditure for the health workforce: evidence and challenges. World health report 2006 background paper. http://www.who.int/nha/docs/ Paper\%20on\%20HR.pdf. Accessed 7 July 2010.

82. World Health Organization (WHO). The world health report 2006 - working together for health. Geneva: World Health Organization; 2006.

83. Huicho L, Scherpbier RW, Nkowane AM, Victora CG, Multi-Country Evaluation of IMCI Study Group. How much does quality of child care vary between workforce with differing durations of training? An observational multi-country study. Lancet. 2008. https://doi.org/10.1016/S01406736(08)61401-4.

84. Mosadeghrad AM, Esfahani P, Afshari M. Strategies to improve hospital efficiency in Iran: A scoping review. Payesh. 2019;18(1):7-21.

85. Mannion R, Davies HT, Marshall M. Cultural characteristics of "high" and "low" performing hospitals. J Health Organ Manag. 2005;19(6):431-9. https:// doi.org/10.1108/14777260510629689.

86. West E. Management matters: the link between hospital organisation and quality of patient care. Qual Health Care. 2001;10(1):40-8. https://doi.org/10. 1136/qhc.10.1.40.

87. Roh C-Y, Jae Moon M, Jung C. Measuring performance of US nonprofit hospitals: do size and location matter? Public Perform Manage Rev. 2010. https://doi.org/10.2753/PMR1530-9576340102.

88. Yong K, Harris AH. Efficiency of hospitals in Victoria under casemix funding: a stochastic frontier approach. Australia: Centre for Health Program Evaluation; 1999.

89. Giancotti M, Guglielmo A, Mauro M. Efficiency and optimal size of hospitals: results of a systematic search. PLoS One. 2017. https://doi.org/10.1371/ journal.pone.0174533.

90. Orendi J. Health-care organisation, hospital-bed occupancy, and MRSA. Lancet. 2008;371(9622):1401-2. https://doi.org/10.1016/S01406736(08)60610-8

91. Cylus J, Papanicolas I, Smith PC, editors. Health system efficiency: How to make measurement matter for policy and management [Internet]. Copenhagen: European Observatory on Health Systems and Policies; 2016. (Health Policy Series, No. 46). Available from: https://www.ncbi.nlm.nih.gov/ books/NBK436888/

92. Walker S, Mason AR, Claxton K, Cookson R, Fenwick E, Fleetcroft R, et al. Value for money and the quality and outcomes framework in primary care in the UK NHS. Br J Gen Pract. 2010;60(574):e213-e20.

\section{Publisher's Note}

Springer Nature remains neutral with regard to jurisdictional claims in published maps and institutional affiliations.
Ready to submit your research? Choose BMC and benefit from:

- fast, convenient online submission

- thorough peer review by experienced researchers in your field

- rapid publication on acceptance

- support for research data, including large and complex data types

- gold Open Access which fosters wider collaboration and increased citations

- maximum visibility for your research: over $100 \mathrm{M}$ website views per year

At BMC, research is always in progress.

Learn more biomedcentral.com/submissions 